\title{
Low IP area and left periphery in Mandarin
} Chinese

\section{Waltraud Paul}

\section{OpenEdition}

\section{Journals}

Édition électronique

URL : http://journals.openedition.org/rlv/1303

DOI : $10.4000 /$ rlv. 1303

ISSN : 1958-9239

Éditeur

Presses universitaires de Vincennes

Édition imprimée

Date de publication : 1 mai 2005

Pagination : 111-134

ISBN : 2-84292-167-4

ISSN : 0986-6124

Référence électronique

Waltraud Paul, «Low IP area and left periphery in Mandarin Chinese », Recherches linguistiques de Vincennes [En ligne], 33 | 2005, mis en ligne le 16 septembre 2005, consulté le 01 mai 2019. URL: http://journals.openedition.org/rlv/1303; DOI : 10.4000/rlv.1303 
Recherches linguistiques de Vincennes 33 - 2005 - p. 111-134

\author{
Waltraud Paul \\ CRLAO, EHESS-CNRS, Paris
}

LOW IP AREA AND LEFT PERIPHERY IN MANDARIN CHINESE*

\begin{abstract}
Belletti's proposal (2003) that the architecture of the domain below IP and above $v \mathrm{P}$ parallels that of the clause-external left periphery is applied to Mandarin Chinese. Though the hierarchy obtained, ' $\mathrm{CP}$ (force) $>$ TopicP $>$ 'even' FocusP $>$ IP $>$ inner TopicP $>$ 'even' FocusP $>v$ ' confirms the parallelism between $\mathrm{CP}$ and the low IP area, it corresponds only partially to the hierarchy postulated by Rizzi (1997, 2002), Belletti (2003), especially with respect to the relative order of topic and focus projections. For in Chinese, no TopicP is allowed below the projection of 'even'-focus (be it clause-externally or clause-internally), nor is ModP, introduced by Rizzi (2002) to host preposed adverbs. These differences are partly due to the identification of topic with old information, an equation not supported by the Chinese data.
\end{abstract}

\title{
KEY-WORDS
}

Mandarin Chinese, left periphery, low IP area, topic, focus, object preposing.

This is an extended version of my talk presented at the workshop on sentence architecture organized by Hans Obenauer in December 2002. I would like to thank Hans for his invitation and for his detailed comments on a preliminary version of this article. I am also grateful to Fu Jingqi and Lu Peng for discussing the intricacies of Chinese syntax and sharing their intutions with me. Last, but not least, I am especially indebted to John Whitman whose suggestions and questions have helped me to sharpen the focus on the issues addressed here. Any errors or shortcomings are my responsibility. 


\section{Introduction}

The present paper takes as a starting point the proposal made by Belletti (2003) that the architecture of the domain below IP and above $v \mathrm{P}$ parallels that of the clause-external left periphery. In particular, we will examine the position between IP and $v \mathrm{P}$ occupied by the object when not in its canonical postverbal position and we will argue for its status as a clauseinternal topic position. The hierarchy we obtain for Chinese is the following: $\mathrm{CP}>$ TopicP $>$ 'even' FocusP $>\mathrm{IP}>$ inner TopicP $>$ 'even' FocusP $>v \mathrm{P}$. This corresponds only partially to the hierarchy postulated by Rizzi $(1997,2002)$, Belletti (2003), especially with respect to the relative positioning of topic and focus projections: in Chinese, no additional TopicP is allowed below the projection of 'even'-focus, neither clause-externally nor clause-internally. We will discuss possible reasons for this discrepancy and provide extensive evidence for the position below IP as the projection hosting the sentenceinternal topic, different from the 'even' focus projection in the IP-domain.

The article is organized as follows. In section two, the semantic properties of the elements occupying the external topic position are discussed in some detail. Chafe's (1976) definition of topic is adopted because it does not reduce topics to "given" elements nor to "what the sentence is about". Section three gives an overwiew of the functional projections constituting the left periphery. CP is head-final in Chinese, with the so-called sentence-final particles (indicating the sentence type) analysed as Comp (section 3.1). TopicP hosts DPs and clauses as well as adverbs (section 3.2). The 'even'focus projection must immediately dominate IP; consequently, Chinese does not have ModP, introduced by Rizzi (2002) for preposed adverbs.

From section four on, we turn to the clause-internal domain and examine the status of DPs below IP and above $v$ P. First, we argue for the necessity of distinguishing between preverbal DPs explicitly marked by lian... ye/dou ('even' focus) and preverbal DPs without any explicit marking (to be analysed as sentence-internal topics). The failure to make this distinction has led to the wrong, though widespread assumption that any clause-internal, but $v$ P-external DP is a focus ( $c f$. Ernst \& Wang 1995, Shyu 1995, 2001; Tsai 2000, Zhang 1997). Second, we give evidence to show that the preposed object DP is not adjoined to $v \mathrm{P}$, but hosted by the functional projection (inner) TopP (section 5). Third, we compare the internal topic projection to the external topic projection and discuss the different constraints observed (section 6). Last, but not least, we demonstrate the differences between the structure with a sentence-internal preposed object and the structure where both the subject and the object have been topicalised to the sentence-external topic position(s), both structures giving rise to the superficially identical SOV order (section 7). We conclude in section eight. 


\section{Preliminaries : topic and focus in Mandarin Chinese}

In the literature dealing with the cartography of the left periphery in CP and IP, which is mainly based on Romance languages (cf. Rizzi 1997, 2002; Belletti 2003, Benincà \& Poletto 2003 among others), a TOPIC is generally understood as representing given, old, non-focus information, whereas FOCUS is employed as tantamount to new or contrastive information ${ }^{1}$. However, topics in Mandarin Chinese are not automatically associated with given, old information (as will also become evident from the numerous examples to be discussed in the text). On the contrary, it is perfectly possible to posit an element carrying new information as the topic of a sentence ${ }^{2}$ :

(1) a. $\mathrm{Ni}$ shenmeshihou lai wo jia? ${ }^{3}$

2SG when come 1SG home

b. Wo jintian mei you kong;

1SG today NEG have time

mingtian ne, dai huir zai shuo ba

tomorrow PART wait while then say PART

'When will you come to my place?

'I can't today; as for tomorrow, well, let's talk about it later.'

(slightly changed example from Chao $1968: 801$ )

(2) Niurou, ni gei wo liang-jin

beef 2SG give $1 \mathrm{SG} 2$-pound

'Give me two pounds of beef.'

(3) Women de fuzhuren, ni renshi ma?

1PL SUB deputy.director 2SG know PART

'Our deputy director, do you know him?'

(Lu Jianming $1980: 34)$

Mingtian 'tomorrow' in (1) followed by the topic marker $n e$ ( $c f$. section 3.2 below) is the "topic of discourse" ( $c f$. footnote 1), but clearly introduces new information. Likewise, (2) with niurou 'beef'in the topic position can be the first sentence uttered by a customer in a butchery. (3) is possible in a context where the person addressed is visiting the office and the speaker tries to elicit information from the visitor in order to decide e.g. to whom he should be introduced. Crucially, (2) and (3) are both felicitous without the DP in topic position being referred to in the preceding discourse nor being singled out by the extra-linguistic context; also note that they are not interpreted contrastively here.

This is the reason why we prefer to adopt Chafe's (1976) definition of TOPIC as the "frame whithin which a sentence holds [...] limit [ing] the applicability of the main predication to a certain restricted domain" rather than the characterization of topic as "what the sentence is about" (à la Li \& 
Thompson 1976), because it is the latter notion which in our opinion has led to the misconception of topic as a necessarily familiar, discourse-given element. Chafe's conception of the topic, however, is neutral with respect to the type of information (old or new) conveyed by the topic ${ }^{4}$.

Furthermore, the notion of focus employed in this article is more restrictive than in e.g. the works cited above. In particular, an element used contrastively does not automatically qualify as a focus. This more constrained conception is motivated by the following considerations.

As illustrated in (4)-(5), topics can be used constrastively:

(4) Shanghai, wo yijing qu-guo

Shanghai $1 \mathrm{SG}$ already go-EXP

keshi Tianjian,wo hai mei qu-guo

but Tianjin 1SG still NEG go-EXP

'I have already been to Shanghai,

but Tianjin, I have not been there yet.'

(5) Zhei-ge xuesheng, wo xihuan, nei-ge, wo bu xihuan

this-CL student 1SG like that-CL 1SG NEG like

'This student, I like, that one, I don't.'

However, a topic can never be focalised by means of shi...de (cf. Paris 1979 : $142 ; 1998: 153,(36),(37))$ :

(6) a. [IPTa shi zai Jiujinshan yujian Zhangsan de]

$3 \mathrm{SG}$ be at San.Franciscomeet Zhangsan DE

'It is in San Francisco that he met Zhangsan.'

b. *[Topp Shi zai Jiujinshan [IP ta yujianZhangsan de]

be at San.Francisco 3SG meet Zhangsan DE

The PP zai Jiujinshan 'at San Francisco'can be clefted with shi... de only when to the right of the subject, but not when in the sentence-initial topic position.

This correlates with the observation that a wh-question word is excluded from the topic position:

(7) a. *[TopP Shei [IP ni renshi]], [TopP shei [IP bu renshi]] ? who 2SG know who NEG know

b. Ni renshi shei, bu renshi shei?

2SG know who NEG know who

'Whom do you know, and whom don't you know?'

Accordingly, it is necessary to distinguish between focus, on the one hand, and contrastive as well as new information, on the other, at least in Mandarin Chinese. For while a topic can be used contrastively and can carry new 
information, its other properties show it to be the exact opposite of focus.

\section{Overview of the left periphery}

The domain above IP in Mandarin Chinese consists of three projections : CP, TopicP and the projection for 'even' focus, in that order.

\subsection{CP}

$\mathrm{CP}$ in Chinese is head-final, headed by the so-called SENTENCE-FINAL PARTICLES indicating the sentence type (force) and analysed as Comp ( $c f$. Gasde \& Paul 1996 and references therein):

$$
\begin{aligned}
& \text { Wo wen-guo Lao Wu } \\
& \text { 1SG ask -EXP } \quad \text { Lao Wu } \\
& \text { 'I HAVE asked Lao Wu.' }
\end{aligned}
$$

(9) $\mathrm{Ni}$ qu ma?

2SG go PART

'Do you go there?'

(10) Ta zuotian pengdao-le shei ne

3SG yesterday meet -PERF who PART

'Whom did he meet yesterday?'

(11) $\mathrm{Ni}$ haohaode xiang xiang ba

2SG well think think PART

'Think it over thoroughly.'

Except for the clear cases of de (in (8)) which strengthens the assertion and $m a$ (in (9)) which indicates a yes/no question, the exact functions of the other complementisers are more difficult to grasp; so far there only exist paraphrases aiming at describing their semantic import ${ }^{5}$. For instance, a $w h$ question is well-formed without ne; if ne is present ( $c f .(10))$, however, the wh-question has to be related to the preceding discourse: "with respect to what you just have said, let me ask you..." ( $c f$. Li \& Thompson 1981 : 306; Chao 1968 : 802). ba in (11) is called "adversative particle" by Chao (1968 : 807) and typically occurs in imperatives. Note that there is no overt complementiser for simple declarative sentences.

\subsection{Topic Phrase}

The constituent in the specifier position of Topic Phrase may be a DP or a clause; the head position Top ${ }^{\circ}$ is optionally realized by the particles $m e$, ne, $a$ etc. ( $c f$. Gasde \& Paul 1996; for TopP in German, cf. Müller \& 
Sternefeld 1993) ${ }^{6}$ :

(12) $\quad\left[{ }_{\mathrm{CP}}\left[{ }_{\mathrm{TopP}}[\mathrm{DP}\right.\right.$ Zhei-ge xuexiao $]$ this -CL school

[IP [DP jiao zhongwen de laoshi] duo ]] [C $\left.\left.{ }^{\circ} \mathrm{ma}\right]\right]$ ? teach Chinese SUB teacher much PART

'In this school, are there many teachers that teach Chinese?'

(13) $\quad\left[\right.$ CP $\left[\right.$ TopP $\left[{ }_{D P} \text { Zhei-ge ren }\right]_{i}\left[{ }_{\text {Top }},\left[\right.\right.$ Top $\left.^{\circ} \mathrm{me}\right]$ this -CL person PART

[IP wo jian-guo $\left.t_{\mathrm{j}}\right]$ ]]] $1 \mathrm{SG}$ see-EXP

'This person, I have already met him.'

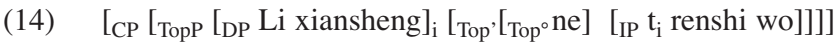
Li Mr. PART know 1SG

'Mr. Li, he knows me.'

(Gasde \& Paul 1996 : 268, (5)-(7))

(15) Zhongguo, da chengshi ne, jiaotong fangbian yi-dian

China big city PART transportation convenient a-bit

'In China, in the big cities, public transport is more convenient.'

(16) Hua a, meiguihua $a_{1}$, wo zui bu ai $t_{i}$ flower PART rose 1SG most NEG love

'Among flowers, roses, I dislike most.'

(C.-C. J. Tang $1990: 338$ )

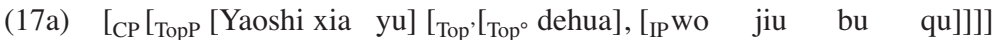
if fall rain PART 1SG then NEG go

'If it rains, I won't go.'

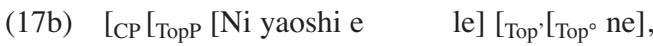
2SG if hungry PART PART

[IP jiu ziji zuo dian chi]]]] then self make a.bit eat

'If you are hungry, make yourself something to eat.'

(Lü et al. 1980/2000: 413)

(18) $\quad\left[{ }_{\mathrm{CP}}\left[{ }_{\text {TopP }}[\text { Zhei-ding maozi }]_{i}\right.\right.$ this -CL hat

[Topp [yinwei wo mei dai gou qian] [IP suoyi mei $\mathrm{m}$ a i

$\left.\mathrm{t}_{\mathrm{i}} \mathrm{]}\right] \mathrm{]}$

because 1SG NEG bring enough money therefore NEG buy

'This hat, because I didn't bring enough money with me, I didn't buy it.'

(Gasde \& Paul 1996 : (17), (27)) 
(12) motivates our analysis where force is in a projection higher than TopicP, the topic zhei-ge xuexiao 'this school' being within the scope of the interrogative complementiser ma. In (13) and (14), the object-DP and the subject-DP, respectively, have moved to the topic position; in the latter case, it is the presence of the topic marker ne which allows us to conclude that the DP Li xiansheng 'Mr. Li' occupies a position above IP. (15), (16), and (18) illustrate multiple topics. Base-generated and moved topics can co-occur and are hosted in recursive TopicP. This holds for DP topics ( $c f .(16))$ as well as for clausal topics: in (18), zhei-ding maozi 'this hat' has raised from the matrix clause, while the yinwei causal clause is base-generated in TopicP. Last, but not least, examples (17) and (18) where TopicP hosts a conditional or a causal clause once again demonstrate that topics do not necessarily convey old information.

\section{3. 'even'-focus}

Only the lian... yeldou 'even' focus is allowed in the domain above IP : lian 'even' introduces the constituent in question and one of the two adverbs, ye 'also' or dou 'all' precedes the VP (for detailed studies, $c f$. Paris 1979a, 1998, Shyu 1995, 2001, among others). The shi... de focus cleft, on the contrary, is restricted to the IP domain ( $c f$. section 4.2 below).

$$
\begin{aligned}
& \text { [FocP Lian xiaohaizi [IP ta }\left[{ }_{v P} \text { dou bu xihuan] }\right] \\
& \text { even child } \quad 3 \text { SG } \\
& \text { all }
\end{aligned}
$$

The object-DP (19a) or the subject DP (20) raises to the 'even' focus projection above IP; (19b) shows that such a projection must equally be postulated below IP ( $c f .4 .1$ below). (21) illustrates that the TopicP must be higher than the 'even'-focus projection (the same relative order holds for topic and 'even'-focus within IP, $c f$. section 5 below); no additional topic projection is, however, available below the focus projection, contrary to Rizzi’s (1997, 2002) proposal :

(21) a. Zhe-ge waiguoren, lian gourou [IP ta ye gan chi] this-CL foreigner even dog.meat 3SG also dare eat 'This foreigner, even dogmeat he dares to eat.'

b. *Lian gourou zhe-ge waiguoren [IP ta ye gan chi] even dog.meat this-CL foreigner 3SG also dare eat 


$$
\begin{aligned}
& \text { Zhe-ge waiguoren, [IP ta lian gourou ye } \\
& \text { this-CL foreigner } 3 \mathrm{SG} \text { even dog.meat also } \\
& \text { 'This fore }
\end{aligned}
$$

The acceptability of (22) with an IP-internal 'even'-projection shows that it is indeed the wrong ordering FocusP $>$ TopP in the left periphery which renders (21b) unacceptable.

\subsection{Adverbs in the left periphery}

It is important to point out that sentential adverbs such as xianran 'obviously, evidently' positionwise pattern with topics i.e., they can only precede, but not follow the 'even'-focus projection:

$$
\begin{aligned}
& \text { a. [CP [TopP Xianran [FocP lian xiaohaizi [IP ta ye taoyan]]]] } \\
& \text { obviously even child } 3 \mathrm{SG} \text { also hate } \\
& \text { 'Obviously, he hates even children.' } \\
& \text { b. *lian xiaohaizi xianran [IP ye taoyan] } \\
& \text { even child obviously 3SG also hate }
\end{aligned}
$$

(23) equally demonstrates that Mandarin Chinese does not have the projection ModP postulated by Rizzi (2002) below the focus projection and above (Top $>$ Fin $>$ ) IP in order to host preposed adverbs ${ }^{7}$.

The paradigm in (24) below consolidates our hierarchy obtained so far 'TopicP > FocusP > IP'; it shows that in the case of multiple topics, all the topics have to precede the 'even'-focus projection and can in no case occupy a position below that projection and above IP (cf. (24c)). Again, this holds both for DP topics and sentential adverbs, which allow permutation only within the recursive TopicP ABOvE the 'even'-focus projection ( $c f .(24 a-b))$. Furthermore, (24b) indicates that like topics, sentential adverbs occupy Spec, TopP and are not adjoined to TopP ( $c f$. Rizzi 1997 : 323):

$$
\begin{aligned}
& \text { a. Xianran yidaliyu lian yi-ge zi Zhangsan ye bu hui jiang } \\
& \text { obviously Italian even 1-CL word Zhangsan also NEG can speak } \\
& \text { 'Obviously, Italian, even one word, Zhangsan cannot speak.' } \\
& \text { b. Yidaliyu xianran lian yi-ge zi Zhangsan ye bu hui jiang } \\
& \text { Italian obviously even 1-CL word Zhangsan also NEG can speak } \\
& \text { 'Italian, obviously, even one word, Zhangsan cannot speak.' } \\
& \text { c. *Yidaliyu lian yi-ge zi xianran Zhangsan ye bu hui jiang } \\
& \text { Italian even 1-CL word obviously Zhangsan also NEG can speak }
\end{aligned}
$$
(Lu Peng 2003 : 224, (116))

The fact that sentential adverbs behave on a par with DP topics in Mandarin Chinese casts doubt on Rizzi's (2002) assumption that only referential nominal expressions are "natural topics" (p. 16), which is one of his main motivations for postulating a separate Mod-projection for adverbs in the left 
periphery, distinct from the topic projection(s). Rizzi's view of what constitutes "natural topics" is once again based on the problematic association of topic with given information. While Rizzi's distinction between DP topics and preposed adverbs might be appropriate for Romance languages, it certainly does not work for Mandarin Chinese, as amply illustrated by the preceding data. Note in this context that, like DP topics, adverbs can be followed by a topic marker such as ne:

Qishi ne, ta bu lai ye hao
actually PART 3SG NEG come also good
'In fact, it's as well that he doesn't come.'
(Lü et al. 1980/2000: 413)

There seems to be no way of construing adverbs such as xianran 'obviously' and qishi 'in fact' as referential nominal expressions, so as to make them conform to Rizzi's characterization of elements liable to appear in TopicP.

The picture we obtain for the left periphery in Mandarin Chinese: ' $\mathrm{CP}$ (force) $>$ Top* $>$ 'even'-focus $>$ IP'is at variance with Rizzi's (2002, (60)) proposal which e.g. predicts another TopicP below FocusP and ModP: 'Force $>$ Top $*>$ Interrogation $>$ Top $*>$ Focus $>$ Mod ${ }^{*}>$ Top $^{*}>$ Fin $>$ IP' $^{8}$. As discussed above, this might partly be due to the different conceptions of topic and focus, but it might also reflect language-specific differences. In the latter case, these differences need to be accommodated and the hierarchy be modified accordingly if one wants to maintain its cross-linguistic validity. In fact, the existence of TopicP BELOw FocusP in Italian has been challenged by Benincà \& Poletto 2003. They claim that the alleged TopicP below FocusP has the syntactic characteristics of focalised elements and constitutes an extension of the focus field. It goes beyond the scope of this article to appraise their proposal, but it is perhaps no coincidence that the same position is problematic in Chinese as well. A re-examination of the architecture in the left periphery might be necessary, especially with respect to the domain postulated below FocusP.

\section{The preposed object as internal topic}

We will now turn to the IP domain and examine whether the hierarchy of projections obtained above IP, viz. 'TopP > FocP' equally holds for the domain below IP. In order to be able to draw the comparison, we first have to identify the function of the projections involved. This requires some discussion, because according to the common assumption, object preposing involves focalisation ( $c f$. Ernst \& Wang 1995, Shyu 1995, 2001, Tsai 2000, Zhang 1997 among others), an assumption that will be shown to be wrong.

The term OBJECT PREPOSING refers to the case where the object - 
WITHOUT any additional marking - occurs between the subject and the verb, more precisely to the left of adverbs, negation and auxiliaries (instead of occupying its canonical postverbal position $)^{9}$ :

$$
\begin{aligned}
& \mathrm{Ni} \text { zhongyao yiqian yong-guo ma } \\
& \text { 2SG Chinese.medicine before use -EXP PART } \\
& \text { 'Have you ever taken Chinese medicine before?' }
\end{aligned}
$$

$\begin{array}{lllll}\mathrm{Ni} & \text { kunqu } & \text { hui } & \text { bu } & \text { hui? } \\ \text { 2SG } & \text { Kunqu.opera } & \text { know } & \text { NEG } & \text { know }\end{array}$

'Do you know how to sing the Kunqu-opera?'

$$
\begin{array}{llll}
\text { Women } & \text { gugong } & \text { qu-guo } & \text { le } \\
\text { 1PL } & \text { imperial.palace } & \text { go-EXP } & \text { PART }
\end{array}
$$

'We have been to the imperial palace before.'

(29) Wo dianying bu kan le

1SG film NEG watch PART

'I won't go to the movies.'

(30) Ta huoche mei ganshang

3SG train NEG catch

'He didn't catch the train.'

(slightly modified examples from FAN Jiyan 1984 : 29)

(31) Ta gourou gan bu gan chi?

3SG dog.meat dare NEG dare eat

'Does he dare to eat dog meat?'

(32) Wo zai meiguo hen duo difang qu-guo

$1 \mathrm{SG}$ at America very much region go-EXP

'I have been to many regions in America.'

(Tsai Mei-chih 1995)

The absence of any markers for the preposed object is important because most studies do not distinguish "bare" object preposing in this strict sense from the obligatory preverbal position of the focalised object in the lian... ye/dou 'even'-focus construction (33) (also cf. (19b), (22) above) and indiscriminately claim the properties of the one construction to equally hold for the other:

$$
\begin{aligned}
& \text { [IP Ta [lian xiaohaizi }\left[{ }_{\nu P} \text { ye bu xihuan]]] } \quad(=(19 b))\right. \\
& \text { 3sG even child also NEG like } \\
& \text { 'He doesn't even like children.' }
\end{aligned}
$$

This lack of precision seems to be at the origin of the widespread misconception that object preposing is tantamount to focalisation. 


\subsection{Object preposing vs. lian... ye/dou 'even' focus construction}

First of all, a simple comparison of sentences (26)-(32) with (33) shows that the semantics of object preposing and the lian... ye/dou construction are completely different. While the latter gives rise to an 'even' interpretation for the element quantified over by lian... ye/dou, this is not the case for object preposing ${ }^{10}$.

Second, this semantic difference is reflected in the different question patterns available. More precisely, in the lian..ye/dou construction the VP itself, being presupposed, cannot be questioned and accordingly, a ' $\mathrm{V}$-not-V' question (34a) is ruled out. A particle question (34b) where the interrogative complementiser $m a$ has scope over the entire sentence or the focalised constituent alone is, however, acceptable ( $c f$. Paris $1998: 142)$ :
a. *Lian Zhangsan ye yao bu yao lai?
even Zhangsan also want NEG want come
b. Lian Zhangsan ye yao lai ma?
even Zhangsan also want come PART
'Does even Zhangsan want to come?'

(Paris 1998 : 142; (7)-(8))

This is in sharp contrast with the acceptability of the ' $\mathrm{V}$-not- $\mathrm{V}$ ' question in the object preposing structure ( $c f$. (27), (31) above). Clearly, there is no bipartition into a presupposed VP and an 'even'-focus object DP here.

Furthermore, as noted by Paris (1994:250), a clausal object can be focalised in the lian... ye/dou construction, but it cannot be preposed (though a corresponding object DP can, $c f$. (36) $)^{11}$ :
a. Ta wang-le [s ji-dianzhong kai hui ] 3SG forget-PERF what.time hold meeting 'He forgot at what time the meeting is.'
b. *Ta [s ji-dian zhong kai hui ] wang-le 3SG what.time hold meeting forget-PERF
c. Ta lian [s ji-dian zhong kai hui ] ye wang-le 3SG even what.time hold meeting also forget-PERF 'He even forgot at what time the meeting is.'
Ta [DP kai hui de shijian] wang-le 3SG hold meeting SUB time forget-PERF
'He forgot the time of the meeting.'

Last, but not least, as known since Hou (1979), [+human] DPs including proper names (of persons) and pronouns cannot be preposed, a restriction which does not hold for the object DP in the lian..ye/dou construction ${ }^{12}$ : 
a. *Li laoshi [zheixie xuesheng $]_{\mathrm{i}}$ qinglai-le $\mathrm{t}_{\mathrm{i}}$

$\mathrm{Li}$ teacher these student invite-PERF

(intended meaning: 'Teacher Li has invited these students.')

b. Li laoshi lian [zheixie xuesheng] ye qinglai-le

$\mathrm{Li}$ teacher even these student also invite-PERF

'Teacher Li has even invited these students.'

(38) a. *Wo Xiaowang bu $_{\mathrm{i}}$ renshi $\mathrm{t}_{\mathrm{i}}$

1SG Xiaowang NEG know

(intended meaning: 'I don't know Xiaowang.')

b. Wo lian Xiaowang ye bu renshi

1SG even Xiaowang also NEG know

'I don't even know Xiaowang.'

a. *Wo-de pengyou $\mathrm{ta}_{\mathrm{i}}$ renshi $\mathrm{t}_{\mathrm{i}}$ 1SG-SUB friend 3sG know

(intended meaning: 'My friends know him.')

b. Wo-de pengyou lian ta ye renshi 1SG-SUB friend even 3SG also know 'My friends know even him.'

We have provided extensive evidence to show that object preposing and 'even' focus involve two separate constructions with distinct syntactic and semantic properties. In the next section, we will demonstrate that object preposing is different from focus clefts as well.

\subsection{Object preposing vs. shi... de focus clefts}

Like sentence-initial external topics ( $c f$. (5) above), preposed objects can be used contrastively:

(40) Wo cai chi-le, fan hai mei chi

1SG vegetables eat-PERF rice yet NEG eat

'I have already eaten the vegetables, but not the rice.'

(Zhu \& Fan 1999: 113)

(41) Wo yi-pian lunwen keyi yingfu,

1SG 1-CL article can cope.with

liang-pian jiu bu xing le

2 -CL then NEG possible PART

'One article, I can handle, but two is impossible.'

(Tsai $1994: 138 ;(32)$ )

But in the same way that this contrastive use cannot be mistaken as indicating the focus status of the sentence-initial topic ( $c f$. section 2 above), it does not constitute proof for a focus status of the preposed object, either.

First, as noted in section 4.1, no bipartition into focus (the preposed 
object) and presupposition (the rest of the sentence including the VP) exists for object preposing sentences. Accordingly, the VP itself can be questioned ( $c f$. (27), (31) above), which would be excluded if the preposed object were really a focus and the VP part of the presupposition. This is confirmed by shi...de focus cleft sentences where the question can only bear on the focused element and where the presupposition must remain unaffected ( $c f$. Paris 1979b; Paul \& Whitman 2001 : (3)-(4)):
a. Ta shi bu shi zai Beijing xue yuyanxue de?
3SG be NEG be at Beijing learn linguistics DE
'Was it in Beijing that he studied linguistics?'
b. $\mathrm{Bu}$ shi, ta shi zai Shanghai xue de
NEG be 3SG be at Shanghai learn DE
'No, it was in Shanghai.'
(43) a. \% Bu shi, ta shi zai Beijing xue fawen de NEG be $3 \mathrm{SG}$ be at Beijing learn French DE (\% 'No, it was in Beijing that he studied French.')

b. $\% \mathrm{Bu}$ shi, ta shi zai Beijing jiao yuyanxue de
$\mathrm{NEG}$ be $3 \mathrm{sg}$ be at Beijing teach lingustics (\% 'No, it was in Beijing that he taught linguistics.')

The infelicity of (43a-b) as possible answers to the question in (42a) indicates that only the focused constituent i.e., the PP zai Beijing 'in Beijing' can be questioned.

Second, the lack of a bipartition into focus vs. presupposition is further illustrated by the possibility of object preposing in list contexts :

$$
\begin{aligned}
& \text { Wo yifu xi -le, di tuo -le, wan shua -le, } \\
& \text { 1SG clothing wash -PERF floor wipe-PERF bowl scrub -PERF } \\
& \text { chuang ye zhengli -le } \\
& \text { bed also put:in:order -PERF } \\
& \text { 'I did the laundry, wiped the floor, washed the bowls and also made the } \\
& \text { bed.' } \\
& \text { (Zhu \& Fan 1999: 113) }
\end{aligned}
$$

Since it implies the non-existence of any other element satisfying the property in question ( $c f$. Paris (1998: 144), to cleft an element is exactly the opposite of listing.

Last, but not least, as observed by Paul \& Whitman (2001), only a postverbal object DP can be clefted by means of shi...de, but not a preposed object:

$$
\begin{aligned}
& \text { a. Women shi qu de gugong } \\
& \text { 1PL be go DE imperial.palace } \\
& \text { 'It's the imperial palace that we have been to.' }
\end{aligned}
$$


b. *Women shi gugong qu de ( $f$. (28) above) $1 \mathrm{PL}$ be imperial.palace go $\mathrm{DE}$

To summarize, object preposing does not involve focalisation, neither 'even' focus nor cleft focus.

\section{The preposed object as internal topic}

We propose to analyse the position occupied by the preposed object as the specifier of a functional projection above $v \mathrm{P}$ (inclusive of $v \mathrm{P}$-adjoined material like adverbs and negation) and below IP (Infl always being covert in Chinese; $c f$. Ernst 1994). This projection hosts the sentence-INTERNAL topic and is different from the Focus Phrase postulated for the 'even'-focus (cf.e.g. Shyu $(1995,2001))$.

As observed in Paul (2002 : 702) and Lu (2003), the inner topic has to precede the 'even'-focus in the IP domain, thus mirroring the order in the left periphery ( $c f$. (21) above) :

a. Qi -mo kaoshi, Lisi yingyu [lian liushi -fen] dou mei nadao term-end exam Lisi English even 60 -point all NEG obtain 'In the final exam, Lisi didn't even obtain 60 points in English.'

b. *Qi -mo kaoshi,Lisi [lian liushi-fen] yingyu dou mei nadao term-end exam Lisi even 60 -point English all NEG obtain Lu $(2003: 223)$

Our analysis differs from Tang (1990 : 170) and Ernst \& Wang (1995) where the preposed object is adjoined to PredP or to (an auxiliary or main) $v \mathrm{P}$, respectively. There exist at least two reasons for rejecting an adjunction analysis $^{13}$.

First, only ONE preposed object is allowed between the subject and the $\nu \mathrm{P}$, though an adjunction scenario would lead us to expect the possibility of multiple adjunction:

$$
\begin{aligned}
& \begin{array}{llllll}
* \mathrm{Ni} & \text { [DP huiyuan } & \text { dahui] } & \text { [DP mingtian } & \text {-de } & \text { richeng] } \\
2 \mathrm{SG} & \text { member } & \text { meeting } & \text { tomorrow } & \text {-SUB } & \text { program }
\end{array} \\
& \text { anpai -hao -le meiyou? } \\
& \text { plan -finish-PERF NEG }
\end{aligned}
$$

('The general membership meeting, have you prepared tomorrow's program?')

$$
\begin{aligned}
& \text { *Ta [DP nei-jian shi] [DPjueding] hai mei zuo ne } \\
& \text { 3SG that-CL matter decision still NEG arrange PART } \\
& \text { ('He has not yet come to a decision concerning that matter.') }
\end{aligned}
$$

Second, the proposal that the preposed object moves to a functional projection 
better explains the extraction facts observed by Fu Jingqi (1994): an object extracted from a non-finite embedded clause cannot adjoin to intermediate VP positions, but must occur to the left of the highest verb ${ }^{14}$ :
a. Ta rang Zhang. pai Xiaop. diaocha -le nei-jian shi 3SG make Zhang. send Xiaop. investigate -PERF that-CL matter
b. Ta [nei-jian shi] rang Zhang. pai Xiaop. diaocha -le 3SG that-CL matter make Zhang. send Xiaop. investigate -PERF 'He asked Zhangsan to send Xiaoping to investigate that matter.'
c. *Ta rang Zhang. [nei-jian shi] pai Xiaop. diaocha -le 3SG make Zhang. that-CL matter send Xiaop. investigate-PERF
d. *Ta rang Zhang. pai Xiaop. [nei-jian shi] diaocha -le 3SG make Zhang. send Xiaop. that-CL matter investigate -PERF (Fu 1994, (15))

If we suppose that non-finite clauses lack the functional architecture postulated for finite ones, the observation in (49) automatically follows: only the matrix verb rang can be dominated by the functional projection TopP hosting the preposed object. Conversely, an object preposed from an embedded FINITE clause is predicted to occur in the TopP above the VP it was extracted from, i.e., to the right of the embedded subject rather than to the right of the matrix subject:
a. Wangwu shuo Lisi [na -ben xiaoshuo $]_{i}$ du -wan -le $t_{i}$ Wangwu say Lisi that-CL novel read-finish-PERF
'Wangwu said that Lisi finished reading that novel.' (from Lu 1994, as reported in Ernst \& Wang 1995 : 244)
b. *Wangwu [na -ben xiaoshuo $]_{\mathrm{i}}$ shuo Lisi du -wan -le $\mathrm{t}_{\mathrm{i}}$ Wangwu that-CL novel say Lisi read-finish-PERF

We have established that the preposed object does not occupy an adjoined position, but the specifier of a functional projection different from and higher than the 'even' FocusP within IP. This functional projection thus shows the same distributional properties as TopP in the left periphery. But this is not the only parallel.

It is commonly acknowledged that the constituent occupying the external topic position can be derived in two ways, either by base-generation or by movement ( $c f$. (12)-(18) above). In fact, base-generation must equally be available for the internal topic (also $c f$. Paul 2002):
a. Ta nei-jian shi hai mei zuo jueding ne 3SG that-CL matter still NEG arrange decision PART 'He has not yet come to a decision concerning that matter.' (Fu 1994, (29); $c f$. (48) above))

b. *Ta hai mei zuo jueding nei-jian shi ne 


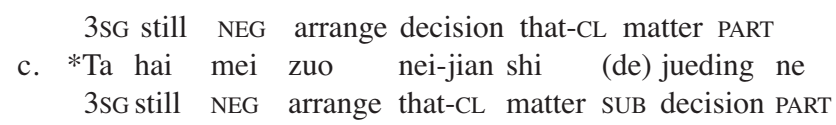
a. Ta yingyu kao -le ge jiushi-fen
3SG English take.exam-PERF CL 90 -point
'He obtained 90 points in the English exam.'
b. *Ta kao -le yingyu ge jiushi-fen
3SG take.exam-PERF English CL 90 -point
c. *Ta kao -le ge jiushi-fen yingyu
3sG take.exam-PERF CL 90 -point English

As illustrated by the unacceptable (b) and (c) sentences, there exists no postverbal position the preverbal DP could have originated from by movement; accordingly, it must have been base-generated. The existence of both base-generation and movement for the preverbal DP provides additional evidence for its analysis as a topic.

Furthermore, as to be expected, the external and the internal topic can co-occur in the same sentence (a possibility completely ruled out for the 'even'-focus); also $c f$. (46a) above :

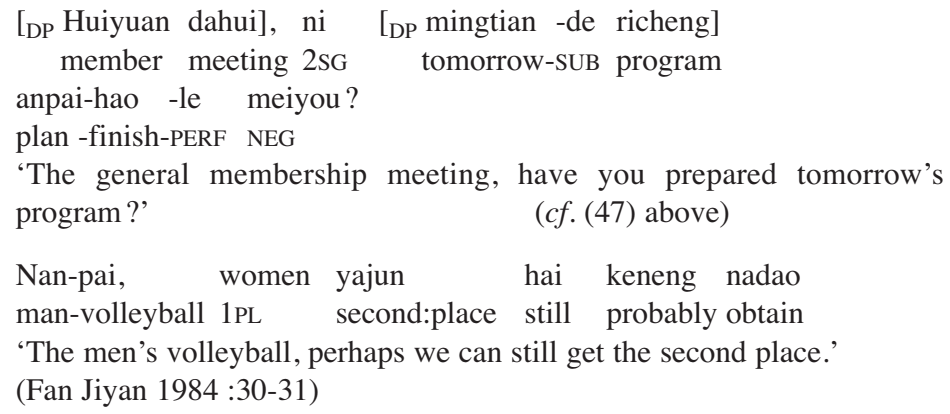

So far we have concentrated on the properties shared by the external and the internal topic position, viz. the existence of a dedicated functional projection TopicP and the possibility of both movement and base-generation. However, there also exist differences between these two topic positions.

\section{The internal vs. the external topic position}

First, only DPs, but no clauses are acceptable in the internal topic position (also $c f$. section 4.1 above). In contrast, the external topic position allows for clauses, both base-generated ( $c f .(17),(18)$ above) and moved:

$$
\begin{aligned}
& \text { a. Ta wang-le [s ji-dianzhong kai hui] } \\
& \text { 3SG forget-PERF what.time hold meeting }
\end{aligned}
$$


'He forgot at what time the meeting is.'

b. *[IPTa [s ji-dianzhong kai hui] wang-le]

3SG what.time hold meeting forget-PERF

c. [TopP [S Ji-dianzhong kai hui] [IP ta wang-le]],

what. time hold meeting 3SG forget-PERF

[TopP [S ji-dianzhong chi fan] [IP ta mei wang]

what. time eat food 3SG NEG forget

'At what time the meeting is, he forgot; at what time the meal is served, he didn't forget.'

Second, while movement to the internal topic position is clause-bound ( $c f$. (50) above), movement to the external topic position is not:
a. *Wangwu [na -ben xiaoshuo] shuo Lisi du -wan -le
Wangwu that-CL novel say Lisi read-finish-PERF
b. [na -ben xiaoshuo] Wangwu shuo Lisi du -wan -le
that-CL novel Wangwu say Lisi read-finish-PERF
c. Wangwu shuo [na -ben xiaoshuo] Lisi du -wan -le
Wangwu say that-CL novel Lisi read-finish-PERF
'That novel, Wangwu said that Lisi finished reading.'
(Lu 1994, from Ernst \& Wang 1995 : 244)

Another important difference between the external topic position and the internal topic position is the fact that multiple topics are allowed in the former (cf. (15)-(18)), but are excluded for the latter ( $c f$. (47)-(48) above). Ultimately, these major differences between the external and the internal TopicP should help us to determine more precisely their feature make up, a task which has to be left for future research.

\section{Double topicalisation $v s$ internal topic}

Despite the clear differences between external and internal topics, in the literature object preposing sentences ( $c f$. (26)-(32) above) have often been analysed as double topicalisation structures, which on the surface also give rise to an 'SOV' order, but where both the object and the subject have moved to the sentence-external topic position(s) ( $c f$. Tang 1990, Lin 1992, Bartos 2003 among others). According to this view, sentence (57) would have the following structure:

$$
\begin{aligned}
& {\left[{ }_{\mathrm{CP}}\left[{ }_{\mathrm{TopP}} \text { Tamen }_{\mathrm{j}}\left[\text { TopP } \text { hhongyao }_{\mathrm{i}}\left[{ }_{\mathrm{IP}} \mathrm{t}_{\mathrm{j}} \text { yijing yong } \text {-guo } \mathrm{t}_{\mathrm{i}} \text { le }\right]\right]\right]\right.} \\
& \text { 3PL Chin. med. already use -EXP PART }
\end{aligned}
$$

As to be discussed later in this section, for [-human] object DPs, the double topicalisation analysis is under certain conditions available for an SOV 
sequence IN ADDITION TO the analysis involving an internal topic.

First, however, we would like to provide an additional argument in favour of our internal topic analysis developed so far. This argument relies on the fact that $w h$-words are excluded from the left periphery and limited to the IP domain :

a. *[TopP Shei [IP ni renshi]], [TopP shei [IP bu renshi]] ? who 2SG know who NEG know

b. Ni renshi shei, bu renshi shei? (=(7) above)

2SG know who NEG know who

'Whom do you know, and whom don't you know?'

a. *[CP [TopP Shei ${ }_{\mathrm{i}}$ ne [IP $\mathrm{t}_{\mathrm{i}}$ zhongyaoyijing yong-guo le]]] ? who PART Chin. med. already use -EXP PART

b. * $\left[_{\mathrm{CP}}\left[_{\mathrm{TopP}} \mathrm{Shei}_{\mathrm{i}}\left[_{\mathrm{TopP}} \quad\right.\right.\right.$ zhongyao $_{\mathrm{j}}$ ne IIP $_{\mathrm{i}}$ yijing yong -guo $t_{\mathrm{j}}$ le] ]] ] ? who Chin. med. PART already use -EXP PART

(58a) illustrates the impossibility of questioning an object DP in the external topic position to the left of the subject. (59a) is unacceptable, because shei 'who' occupies the external topic position, as indicated by the presence of the topic marker ne. (59b) is rejected for the same reason; shei 'who' appears to the left of the topicalised object DP (marked by ne) i.e., in a position clearly outside IP.

Against this background, the acceptability of shei 'who' questioning the subject in (60) demonstrates conclusively that both the subject DP and the object DP are within IP; hence zhongyao 'Chinese medicine' occupies the internal topic position.

$$
\begin{aligned}
& \text { [IP Shei zhongyao }_{i} \quad \text { yijing yong -guo } t_{i} \text { le]? } \\
& \text { who Chinese.medicine already use -EXP PART }
\end{aligned}
$$

Shei can also serve as a test to show that what at first sight looks like a sentence with a [+human] DP as internal topic ${ }^{15}$ in fact involves a double topicalisation structure where the subject DP Li laoshi 'teacher Li' - being topicalised - can precisely not be questioned:

$$
\begin{aligned}
& \text { [TopP Li laoshi } \left._{\mathrm{j}} / \text { shei }_{\mathrm{j}} \text { [TopP }_{\text {T }} \text { zheixie } \quad \text { xuesheng }\right]_{\mathrm{i}} \text { IIP }_{\mathrm{j}} \\
& \text { qinglai } \left.\left.- \text { le } \mathrm{t}_{\mathrm{i}}\right] \mathrm{]}\right] \\
& \text { Li teacher/ who these student invite -PERF } \\
& \text { 'Teacher Li has invited these students.' (cf. (37a)) }
\end{aligned}
$$

Consequently, only SOV sequences with a [-human] object DP can be subject to two structural analyses. If (at least) one of the DPs is accompanied by a topic marker, we obtain a double topicalisation structure (62), whereas 
without any topic marker, the sentence is analysed as an IP with an internal topic (63):

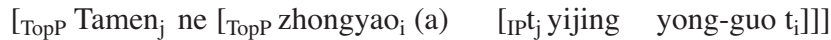

$$
\begin{aligned}
& \text { 3PL PART Chin.med. PART already use -EXP } \\
& \text { [IP Tamen [int. Topp zhongyao }{ }_{i}\left[{ }_{v P} \text { yijing yong -guo } t_{i}\right] \text { ] } \\
& \text { 3PL Chin.med. already use -EXP }
\end{aligned}
$$

This section has established the fundamental differences between the internal topic structure and the double topicalisation structure, introducing the (un) acceptability of a subject question as a crucial test here ${ }^{16}$.

\section{Conclusion}

Belletti's proposal (2003) that the architecture of the domain below IP and above $v \mathrm{P}$ parallels that of the clause-external left periphery has been confirmed for Mandarin Chinese. The hierarchy itself, however, viz. ' $\mathrm{CP}$ (force) $>$ TopicP $>$ 'even' FocusP $>$ IP $>$ inner TopicP $>$ 'even' focusP $>v \mathrm{P}$ 'corresponds only partially to that postulated by Rizzi $(1997 ; 2002)$ and Belletti (2003), especially with respect to the relative order of topic and focus projections. First, no additional TopicP is allowed below the projection of 'even'-focus in Chinese, be it clause-externally or clause-internally. Second, there exists no evidence in Chinese for a separate ModP (below FocusP) hosting adverbs in the left periphery. Instead, adverbs behave on a par with DP topics and occur in the same topic projection(s). Third, for the IP domain, Chinese shows the exact opposite of the order proposed by Belletti (2003) for Romance which is Focus $>$ Topic. Admittedly, there remain open questions in this limited overview of the CP and IP periphery in Chinese, for instance the reason why clausal topics are excluded from the internal topic position, but allowed in the external topic position, and the different constraints on DPs in the external vs. internal topic position. However, it seems evident that the notions such as TOPIC and FOCUS need to be applied more coherently in order to guarantee the commensurability of phenomena studied across languages.

\section{NOTES}

1. "With TOPICALIZATION of an element I refer here to the process through which that element is dealt with as the TOPIC of discourse, the GIVEN information. In the literature the term TOPICALIZATION often indicates the process that we here refer to as FOCALIZATION : the singling out of an element of the clause as the NEW or CONTRASTIVE information." (Belletti 2001: note 1.)

2. Since for us, topic is not automatically equivalent to old information, in the 
remainder of the text, the term TOPIC is used as short for the constituent occupying a topic position (sentence-external or sentence-internal).

3. The following abbreviations are used in glossing examples: CL classifier; EXP experiential aspect; NEG negation; PART particle; PERF perfective aspect; PL plural (e.g. 3PL = 3rd person plural); SG singular; SUB subordinator.

4. " $[\ldots]$ The following are typical Mandarin sentences with topics, provided by Li and Thompson:

(i) Nei-xie shumu shu-shen da those tree tree-trunk big

(ii) Nei-ge ren yang ming George Zhang that person foreign name George Zhang

[...] But what is such a topic? The examples I have seen do not fit precisely the characterization that a topic is "what the sentence is about" [...]. If one considers, for example, what bigness is predicated of in the first sentence, it is not 'those trees', but rather their trunks. WHAT THE TOPICS APPEAR TO DO IS TO LIMIT THE APPLICABILITY OF THE MAIN PREDICATION TO A CERTAIN RESTRICTED DOMAIN. The bigness of trunks applies within the domain of those trees. [...] Typically, it would seem, THE TOPIC SETS A SPATIAL, TEMPORAL, OR INDIVIDUAL FRAMEWORK WITHIN WHICH THE MAIN PREDICATION HOLDS. [...] In brief, 'real topics'(in topic prominent languages) are not so much "what the sentence is about" as "the frame within which the sentence holds."

(Chafe 1976: 50-51, on 'topics, Chinese style'; emphasis mine.)

5. For a complete overview of the so-called sentence-final particles, $c f$. Chao (1968, ch. 8.5), Li \& Thompson (1981, ch. 7), and a vast literature in Chinese.

6. $M e, n e, a$, etc. are in general treated as simple pause particles. However, their distribution is not as free as this label suggests: ne e.g. is barred from the IP domain and can only occur in the left periphery ( $c f$. section 7 below).

7. Rizzi's (2003: 17) justification for the adverb positions in the left periphery is as follows: "Preposed adverbs can occupy at least three distinct structural positions in the left periphery. Normally, they occupy a dedicated position [i.e., ModP, W.P.] which is intonationally similar to a topic position, but differs from it in that the adverb position does not require a connection with the previous discourse context. [...] when they have been mentioned in the immediately preceding discourse, preposed adverbs can also be moved to a genuine topic position [...] And, on top of these two options, adverbial elements can also be moved to the initial focus position [...]."

8. Too little is known about the detailed architecture of the left periphery in Mandarin Chinese to be able to argue for or against projections such as Interrogation and Finiteness. We therefore limit ourselves to TopP and FocusP here.

9. The very position of the preposed object DP invalidates Zhang's (1997) analysis where the object moves to the inner spec of $v$. Her other claims are equally untenable i.e., to associate object preposing with focalisation and to liken it to OBJECT SHIFT. The latter view is also (wrongly) adopted by Soh (1998), notwithstanding the well-known fact that the verb does not leave the $v \mathrm{P}$ in Chinese.

10. The 'even' interpretation also obtains without lian, which has probably favoured the amalgam of object preposing and 'even' focus. However, the obligatory presence of ye/dou and the associated 'even' interpretation still suffice to distinguish the two cases. 
11. Thanks to Fu Jingqi for the minimal quadruple (35)-(36).

12. (37a)-(39a) are acceptable when analysed as ' $D P_{i}, D P V t_{i}$ 'resulting in 'Teacher Li, these students have invited him' for (37a). In other words, when it is possible to interpret the second DP in a sequence 'DP DP VP' as the subject of the sentence (which is quasi-automatically the case when it is [+human]), the interpretation 'Topic ${ }_{i}$, Subject $\mathrm{V} \mathrm{t}_{\mathrm{i}}$ ' is chosen. This observation was made by C.-T. James Huang in his MA thesis (Huang, p.c.; also $c f$. Li Linding 1986, Xu Shu 1988), but so far no explanation in more formal terms has been proposed. For further discussion of the prohibition against preposing of [+human] DPs to an IP-internal position, $c f$. section 7 below.

13. Tsai (2000) also argues against an adjunction approach and in favor of a functional projection as host for the preposed object. However, he assumes that this FP is "headed by an implicit focus feature" and that it "defines the domain of contrastive focus" (p. 4).

14. Fu (1994) herself interprets this kind of extraction data as an argument in favour of object preposing as IP-adjunction rather than VP-adjunction. More precisely, she suggests that the preposed object occupies the lower specifier position of IP, whereas the subject is in the higher specifier of IP. This analysis is however invalidated by the acceptability of adverbs between the subject and the preposed object ( $c f$. (32) above).

15. Recall that [+human] DPs are excluded from the internal topic position ( $c f$. section 4.1 above); no such constraint exists for the external topic position.

16. Ernst \& Wang (1995) also argue against the analysis of object preposing sentences as double topicalisation structures, but they mainly use arguments based on the wrong assumption that object preposing is focalisation. Likewise, Tang (1990: 169 , fn 10) discusses one case where she intuitively prefers the object preposing analysis to the double topicalisation analysis.

\section{REFERENCES}

BARTOS, Huba (2003). Locating the subjects in Mandarin Chinese. Acta Orientalia Hungarica 56: 149-172.

Belletti, Adriana (2003). Aspects of the low IP area. In Rizzi, L. (ed.).

BenincÀ, Paola; Poletto, Cecilia (2003). Topic, focus and V2: defining the CP sublayers. In Rizzi, L. (ed.).

Chafe, Wallace (1976). Givenness, Contrastiveness, Definiteness, Subjects and Topics. In LI, Charles N. (ed.). 25-55.

Chao, Yuen Ren (1968). A grammar of spoken Chinese. Berkeley et alibi : University of California Press.

ERnst, Thomas (1994). Functional categories and the Chinese Infl. Linguistics 32-2: 191-212.

ERnst, Thomas; WANG, Chengchi (1995).Object Preposing in Mandarin Chinese. Journal of East Asian Linguistics 4-3 : 235-260.

FAN, Jiyan (1984). Duo-xiang NP ju [Sentences with multiple NPs]. Zhongguo yuwen $1984, n^{\circ} 1: 28-34$. 
Fu, Jingqi (1994). SOV word order in Chinese and IP specifier. Paper presented at NACCL-6, University of Southern California.

Gasde, Horst-Dieter; Paul, Waltraud (1996). Functional categories, topic prominence, and complex sentences in Mandarin Chinese. Linguistics 34-2: 263-294.

Hou, John Yien-Yao (1979). Grammatical Relations in Chinese. Doct. dissertation, University of Southern California, Los Angeles.

Li, Charles N. (ed.) (1976). Subject and Topic. New York: Academic Press.

Li, Charles N.; Thompson, Sandra A. (1976). Subject and Topic: a new typology of language. In LI, Charles N. (ed.). 457-489.

LI, Linding (1986). Xiandai hanyu juxing [Sentence patterns of modern Chinese]. Beijing: Shangwu yinshuguan.

LIN, Jowang (1992). The syntax of zenmeyang 'how' and weishenme 'why' in Mandarin Chinese. Journal of East Asian Linguistics 1-3 : 293-331.

Lu, Hui-chuan (1994). Second preverbal NPs in Chinese. Paper presented at NACCL6, University of Southern California.

LU Jianming (1980). Hanyu kouyu jufa li de yiwei xianxiang. [Inversion in the grammar of spoken Chinese]», Zhongguo yuwen 1980, $\mathrm{n}^{\circ} 1: 28-41$.

Lu, Peng (2003). La subordination adverbiale en chinois contemporain. Doct. dissertation, Université Paris 7.

LÜ Shuxiang et al. (eds.) (1980/2000). Xiandai hanyu babaici [Eight hundred words of modern Chinese]. Beijing: Shangwu yinshuguan.

Müller, Gereon; Sternefeld, Wolfgang (1993). Improper movement and unambiguous binding. Linguistic Inquiry 24-3: 461-507.

PARIs, Marie-Claude (1979a). Some aspects of the syntax and semantics of the lian... yeldou construction in Mandarin. Cahiers de linguistique - Asie orientale 5 : 47-70.

PARIS, Marie-Claude (1979b). Nominalization in Mandarin Chinese. Paris: Département de recherches linguistiques, Université Paris 7.

PARIs, Marie-Claude (1994). Position syntaxique et valeur discursive: le cas de même en chinois. Cahiers de linguistique - Asie orientale 23-1/2: 241-253.

PARIS, Marie-Claude (1998). Focus Operators and Types of Predication in Mandarin. Cahiers de linguistique - Asie orientale 27-2: 139-159.

Paul, Waltraud; Whitman, John (2001). The complement structure of shi... de clefts. Ms., CRLAO, Paris \& Cornell University.

PAul, Waltraud (2002). Sentence-internal topics in Mandarin Chinese: the case of object preposing. Language and Linguistics (Academia Sinica, Taiwan) 3-4 : 695-714.

RIzZI, Luigi (1997). The fine structure of the left periphery. In HAEGEMAN, Liliane (ed.), Elements of Grammar: 281-337. Dordrecht et alibi : Kluwer.

RIzzI, Luigi (2002). Locality and left periphery. In Belletti, A. (ed.), Structures and beyond. The cartography of syntactic structures, vol. 3. Oxford: Oxford University Press.

RIzzI, Luigi (ed.) (2003). The Structure of IP and CP. The cartography of syntactic structures, vol. 2. Oxford: Oxford University Press. 
SoH, Hooi Ling (1998). Object scrambling in Chinese. Doctoral dissertation, MIT.

SHYU, Shu-ing (1995). The Syntax of Focus and Topic in Mandarin Chinese. Doct. dissertation, University of Southern California, Los Angeles.

SHYU, Shu-ing (2001). Remarks on object movement in Mandarin SOV order. Language and Linguistics (Academia Sinica, Taiwan) 2-1: 93-124.

TsaI, Mei-chih (1995). La Modification adverbiale et l'ordre des mots en chinois. Doct. dissertation, Université Paris 7.

TsaI, Wei-tian (2000). Object Fronting and Focus Placement in Chinese. Paper presented at the International Symposium on Topic and Focus in Chinese, Hong Kong Polytechnic University, June 21-22, 2000.

TANG, Chih-Chen Jane (1990). Chinese Phrase Structure and the extended X-bar Theory. Doct. dissertation, Cornell University.

XU, Shu (1988). Cong yufa, yuyi he yuyong jiaodu tan 'ming (shou) + ming (shi) + dong' jushi [On the syntax, semantics and pragmatics of the structure 'NP (patient) + NP (agent) + verb]. Yufa yanjiu he tansuo 6: 50-63.

Zhang, Ning (1997). Syntactic Dependencies in Mandarin Chinese. Doct.

\section{RÉSUMÉ}

L'hypothèse de Belletti (2003), selon laquelle l'architecture fonctionnelle à l'intérieur d'IP reflète celle au-dessus d'IP, est examinée pour le mandarin. Tandis que le parallélisme entre CP et la partie basse d'IP se trouve confirmé, la hiérarchie obtenue pour le mandarin, ' $\mathrm{CP}$ (force) $>$ TopP $>$ FocusP 'même' $>$ IP $>$ TopP interne $>$ FocusP 'même' $>v \mathrm{P}$ ', ne correspond que partiellement à celle proposée par Rizzi $(1997,2002)$ et Belletti (2003), surtout en ce qui concerne l'ordre relatif entre topique et focus. En effet, en mandarin un TopP au-dessous de FocusP est exclu aussi bien dans CP que dans IP et il n'y a pas non plus de ModP dans la périphérie gauche, projection introduite par Rizzi (2002) pour abriter des adverbes déplacés. Ces différences s'expliquent partiellement par l'idée reçue que le topique véhicule toujours de l'ancienne information, idée clairement infirmée par le mandarin.

\section{MotS-CLÉS}

Mandarin, périphérie gauche, périphérie d'IP, topique, focus, antéposition d'objet. 